\title{
PHYSIOLOGICAL AND GROWTH RESPONSE OF TOMATO PLANTS AFTER TRICHODERMA SPP. SEED TREATMENTS
}

\author{
CRISTINA PETRISOR ${ }^{\mathrm{a}}$, ALEXANDRU PAICA $^{\mathrm{b}^{*}}$, FLOAREA BURNICHI $^{\mathrm{c}}$
}

\begin{abstract}
Different isolates of Trichoderma are able to produce metabolites which induce some morphological and physiological changes in plant such as enhanced plant growth and response to plant pathogens or reduced plant stress. The aim of the present study is to evaluate the effect of some Trichoderma isolates on plant growth promoting and physiological parameters of tomato plants. Also, the Trichoderma isolates were assessed based on IAA (indole 3-acetic acid) production and ability to solubilize phosphate, traits associated to growth. Tomato seed treatment with Trichoderma isolates led to a significant increase in plant height as well as root length and root fresh/ dry weight. However, metabolite production varied among isolates and depends on the isolate. Our data indicated that three of the Trichoderma isolates studied increase leaf pigments content and improve the photosynthetic activity of tomato plants.
\end{abstract}

Keywords: chlorophylls, carotenoids, IAA, root length, fresh weight

\section{INTRODUCTION}

Trichoderma spp. are known to interact with plants resulting in beneficial effects such as stimulation of plant defense, development of roots, promotion of plant growth, activation of seed germination, increase of chlorophyll content and photosynthetic efficiency, amelioration of abiotic stress, resistance to membrane pore-forming agents, and enhancement of nutrient uptake $[1,2,3]$.

\footnotetext{
${ }^{a}$ Research and Development Institute for Plant Protection, Bdv. Ion lonescu de la Brad, No.8, District 1, Bucharest, Romania.

${ }^{b}$ Institute of Biology, Romanian Academy, Splaiul Independentei, No. 296, Bucharest, Romania.

c Research and Development Station for Vegetables Buzau, Mesteacanului Street, No.23, Buzau, Romania

*Corresponding author: e-mail: paicaalexandru@gmail.com
} 
Trichoderma spp is a genus of fungi that has been reported to be suited for maintaining soil quality and promoting plant growth, by enhancing the availability of nutrients and minerals for plants, producing phytohormones and siderophores even in the absence of pathogens $[4,5,6,7,8,9,10,11]$. The growth promoting potential of Trichoderma spp. has been extensively studied on cucumber, onions, rice, soybeans, tomatoes, radish, bean, chickpea, pepper $[7,12,13,14,15,16,17,18,19]$. However, studies of De'Souza et al., (2008) [20] showed that Trichoderma stromaicum colonized endophytically cacao seedlings but was unable to induce plant growth.

Studies of Altomare et al., (1999) [21] revealed that Trichoderma harzianum strains convert phosphate to a soluble form through chelation mechanisms, thus suggesting a possible mechanism involved in plant growth promotion. Different Trichoderma strains have been reported to produce and release indole-3-acetic acid (IAA) and auxin related compounds in the culture medium. These have a positive effect on root morphology and development $[6,9,14,22]$.

Mastouri et al. (2010) [23] found that tomato seed treatment with Trichoderma harzianum accelerates germination of seeds and increases seedling vigour. Priming and seed coating with Trichoderma harzianum were the most effective treatments in stimulating vegetative growth of pea plants,causing significant increase in early and total green pod yield [24].

This research was conducted in order to investigate the effect of different Trichoderma spp. isolates on physiological and growth parameters of tomato plants.

\section{RESULTS AND DISCUSSION}

Results revealed changes in plant height, root length, root fresh weight and root dry weight in tomato treated with Trichoderma isolates.

Tomato plants obtained from seeds treated with Trichoderma isolates were grown in pots in a growth chamber for 4 weeks. The heights of the plants were measured at the end of the 4-week period.

Application of Trichoderma to tomato seeds enhanced the tomato height plant within 4 weeks A pronounced increase in plant height was observed for Trichoderma treated tomato plants, which varied between 25.22 $\mathrm{cm}$ (M2_14) and $28.28 \mathrm{~cm}$ (T85), while the mean height for chemical control (Cropmax) and blank control (no treatment) were recorded at $24.36 \mathrm{~cm}$ and $22.8 \mathrm{~cm}$ respectively (table 1 ). The height of tomato plants was noticeably increased when seeds were treated with T85 and T50 compared to the other isolates. These results are in accordance with those of Doni et al. (2014) [7] who obtained an increased height in rice plants treated with Trichoderma. 
Our findings are also comparable to another study that described the growth improvement of chickpea after treatments with Trichoderma [18].

Table 1. Effect of Trichoderma treatments on growth parameters of tomato seedlings

\begin{tabular}{|c|c|c|c|c|c|}
\hline $\begin{array}{l}\text { Fungal } \\
\text { isolates }\end{array}$ & \begin{tabular}{|c|} 
Plant height \\
$(\mathrm{cm})$
\end{tabular} & no. of leaves & $\begin{array}{l}\text { Root length } \\
\text { (cm) }\end{array}$ & $\begin{array}{l}\text { Root fresh weight } \\
\text { (g) }\end{array}$ & $\begin{array}{l}\text { Root dry } \\
\text { weight }(g)\end{array}$ \\
\hline Blank Control & $22.8 \pm 0.76$ & $15.13 \pm 0.34$ & $10.05 \pm 0.04$ & $1.91 \pm 0.21$ & $0.91 \pm 0.21$ \\
\hline $\begin{array}{l}\text { Chemical } \\
\text { control }\end{array}$ & $24.36 \pm 0.65$ & $14.72 \pm 0.36$ & $10 \pm 0.02$ & $2.39 \pm 0.56$ & $1.78 \pm 0.12$ \\
\hline T85 & $28.28 \pm 0.34$ & $15.41 \pm 0.23$ & $10.45 \pm 0.04$ & $4.45 \pm 0.23$ & $2.93 \pm 0.09$ \\
\hline T50 & $27 \pm 0.01$ & $15.5 \pm 0.21$ & $10.33 \pm 0.06$ & $3.39 \pm 0.32$ & $1.9 \pm 0.18$ \\
\hline M14 & $\begin{array}{c}25.76 \pm \\
0.12\end{array}$ & $15.84 \pm 0.04$ & $10.5 \pm 0.06$ & $2.21 \pm 0.05$ & $0.98 \pm 0.31$ \\
\hline M2_14 & $25.22 \pm 0.15$ & $15.88 \pm 0.05$ & $8 \pm 0.02$ & $2.08 \pm 0.12$ & $0.88 \pm 0.24$ \\
\hline
\end{tabular}

The data are expressed as means \pm SDV (standard deviation) of three replicates of each experiment

Similar results were reported in radish by Mukhopadhay and Pan (2012) [25]. Also, Hoyos-Carvajal et al. (2009) [9] demonstrated that Trichoderma isolates increased the shoot and root length of Vigna mungo (black gram) thirty days after sowing.

Tucci et al. (2011) [17] demonstrated that the growth stimulation is dependent on the tomato genotype, suggesting that the response to Trichoderma treatment is genetically controlled. Their data show the ability of Trichoderma harzianum T22 to increase canopy and stem growth in tomato, and at the same time to modify the root architecture through increasing root length or through development of lateral roots. No significant differeces were found regarding the number of leaves of all tomato plants inoculated with Trichoderma isolates in comparison to blank control and chemical control (table 1). These results are in agreement with data of Azarmi et al. (2011) [12], who reported that seed inoculation with Trichoderma had no significant effect in leaf number and also in total area of leaf and plant height, root fresh and dry weight. However, their results supported that tomato grown on soil amended with Trichoderma sp. had also a marked increase in leaf number, leaf area and chlorophyll content. However, the results of other experiments performed by Ozbay and Newman, (2004) [26] show an increase in leaf number and area and shoot length of tomato plants treated with Trichoderma isolates. 

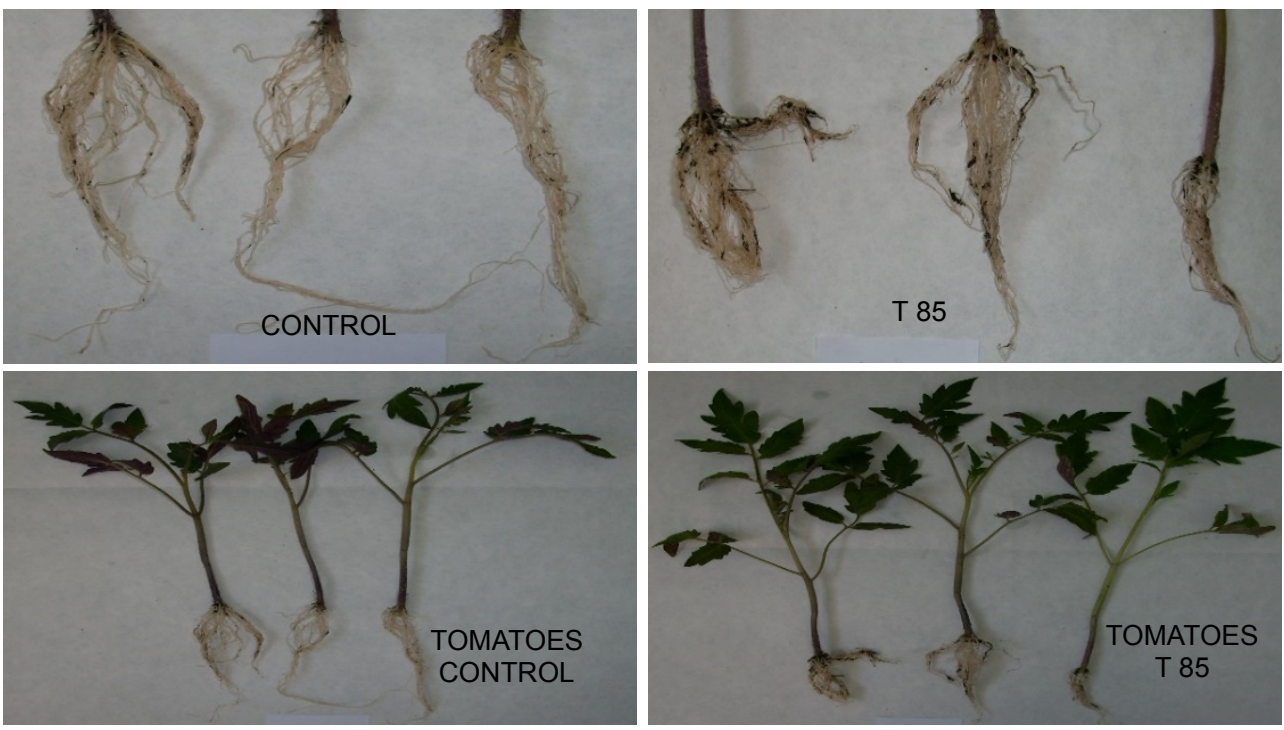

Fig. 1. Effects of Trichoderma treatments on the growth and development of tomato roots and plants

Root development of seedlings was not significantly affected by Trichoderma treatments (fig. 1). Root length was increased for the treated tomato plants. Root lengths ranged between $8 \mathrm{~cm}$ and $10.45 \mathrm{~cm}$, compared to blank control and chemical treatment control which were recorded at 10 $\mathrm{cm}$. According to the data shown in table 1 the fresh weight and dry weight of tomato roots treated with Trichoderma was larger than blank control and treated plants with chemical fertilizer. These results show that Trichoderma treatments had a meaningful influence on root mass of tomato plants more so than on root length.

Ozbay\& Newman (2004) [26] have shown that some isolates of Trichoderma harzianum did not have a significant effect on fresh or dry root mass of tomato plants. Jang et al. (1993) [27] reported that cucumber growth was promoted when seeds were coated with conidia of Trichoderma and Gliocladium isolates. Also, they describe the growth promoting effect of the two fungal cultures on oat coleoptile segment elongation, which was influenced by filtrate concentration and time of the exposure to the culture filtrate.

The observed increase of plant height and root length in this study may be attributed to the ability of the Trichoderma isolates to produce IAA and enhance nutrient uptake. Our data indicate that all Trichoderma isolates (fig. 2) used in this work synthesize IAA. However production of IAA varied among the isolates. Isolates T85 and T50 produced the highest amount of IAA ranging between 15.9-19.8 $\mu \mathrm{g} / \mathrm{ml}$ (table 2). 


\section{PHYSIOLOGICAL AND GROWTH RESPONSE OF TOMATO PLANTS AFTER TRICHODERMA SPP. SEED TREATMENTS}

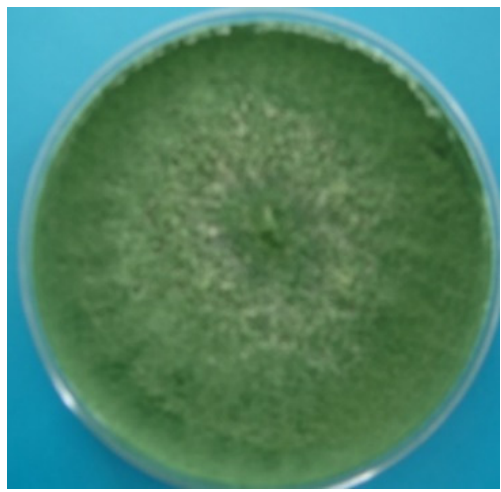

Fig. 2. Characteristic aspects of Trichoderma Td 85 straincultures

Our results are quantitatively lower than those reported by Kotasthane et al. (2015) [28] and Salas-Marina et al., (2011) [29] which found ranges of 27-30.08 $\mu \mathrm{g} / \mathrm{ml}$ for IAA produced by Trichoderma isolates. All Trichoderma isolates studied cultured in medium without precursor produced low levels of IAA. When L- tryptophan was included in the medium, there was a 13-25fold increase in production of IAA for T85 and T50 compared to the control without precursor (table 2).

Table 2. Production of IAA and phosphate solubilization by Trichoderma isolates

\begin{tabular}{|c|c|c|c|c|}
\hline Isolates & \multicolumn{2}{|c|}{$\mathrm{IAA}(\mu \mathrm{g} / \mathrm{ml})$} & $\begin{array}{c}\text { Phosphate } \\
\text { solubilization } \\
\text { index }\end{array}$ & $\begin{array}{c}\text { Phosphate } \\
\text { solubilization } \\
\text { (mg/l) }\end{array}$ \\
\hline & With tryptophan & Without tryptophan & & \\
\hline T85 & $15.9 \pm 0.02$ & $1.2 \pm 0.11$ & 0 & $0.18 \pm 0.01$ \\
\hline T50 & $12.8 \pm 0.03$ & $1.0 \pm 0.10$ & 0 & $0.25 \pm 0.01$ \\
\hline M14 & $10.1 \pm 0.03$ & $0.8 \pm 0.03$ & 0 & 0 \\
\hline M2_14 & $5.9 \pm 0.10$ & $0.7 \pm 0.04$ & 0 & 0 \\
\hline
\end{tabular}

The data are expressed as means \pm SDV (standard deviation) of three replicates of each experiment

The capacity of Trichoderma to produce phytohormones (IAA) or analogue substance was reported by earlier studies $[5,6,9,10,14,22,30]$ and this is the main mechanism involved in plant growth promotion. Contrary to aforementioned studies, experiments of Sofo et al. (2011) [31] showed that $T$ harzianum T22 did not produce phytohormones in growing media, suggesting that T22 is able to induce hormone synthesis ex novo in the plants. 
Contreras-Cornejo et al. (2009) [6] have shown that strains of Trichoderma atroviride and Trichoderma virens stimulated lateral root development, increased biomass production and reduced primary root length by producing IAA and auxin like compound in their studies on Arabidopsis thaliana. Also, Zhao and Zhang (2015) [19] found that IAA level, root length and fresh root weight of cucumber seedling were increased after treatment with $T$. asperellum. Also, results of Ortega-Garcia et al. (2015) [16] supported that differences in growth stimulation by $T$. asperellum isolates is related to their ability to secrete of IAA like compounds in presence of precursors. Similar results were obtained by Chowdappa et al. (2013) [22] who demonstrated that Trichoderma harzianum OTPB3 produced higher quantities of IAA in culture broth.

The importance of phosphate solubilizing fungi consists in increasing phosphate uptake for plant growth. In this study none of the Trichoderma isolates tested was able to solubilize the phosphate on Pikovskaya's medium (table 2). Although none of the isolates produced any detectable solubilization zone (halo) in plate PVK agar assay, T85 and T50 shown a slight solubilization between 0.18 and $0.25 \mathrm{mg} / \mathrm{l}$ in liquid medium. Thus, plant growth promotion of tomato plants studied in our experiment correlates with IAA production but not with phosphate solubilization. However, some reports indicate the ability of Trichoderma spp. to solubilize tricalcium phosphate, suggesting their applicability in crop fields as biofertilizers promoting plant growth $[5,12,21]$. Production of plant phytohormones by Trichoderma might led to higher photosynthetic rates and an enhanced growth response. The leaf chlorophyll a, b, and total chlorophyll contents in tomato treated with Trichoderma were increased for all variants with the exception of chemical control and M2_14. This indicates that the treatment with T85 and T50 isolates caused increase assimilation pigments content compared to blank control and chemical control. The content of chlorophyll $a$ in tomato inoculated with T85 (194.95 $\mu \mathrm{g} / \mathrm{ml})$ and T50 $(190.46 \mu \mathrm{g} / \mathrm{ml})$ was higher compared to the blank control $(182.95 \mu \mathrm{g} / \mathrm{ml})$ and chemical control $(154.96 \mu \mathrm{g} / \mathrm{ml})$. The results also revealed that plant treated with Trichoderma has higher carotenoids content compared to control. All this data supported that plants treated with Trichoderma have heightened photosynthetic rates. Similar results were also reported by Fiorini et al. (2016) [30] who indicated that application of Trichoderma T6776 on tomatoes seed enhanced the content of all leaf pigments with an increase ranging from 73 to $76.5 \%$ compared to control. 
Table3. Effects of Trichoderma treatments on physiological parameters content of tomato plants

\begin{tabular}{|l|c|c|c|c|}
\hline \multicolumn{1}{|c|}{ Fungal isolates } & $\begin{array}{c}\text { Chlorophyll } a \\
\mu \mathrm{g} / \mathrm{ml}\end{array}$ & $\begin{array}{c}\text { Chlorophyll } b \\
\mu \mathrm{g} / \mathrm{ml}\end{array}$ & $\begin{array}{c}\text { Carotenoids } \\
\mu \mathrm{g} / \mathrm{ml}\end{array}$ & $\begin{array}{c}\text { Chl }(a+b) \\
\mu \mathrm{g} / \mathrm{ml}\end{array}$ \\
\hline Control & $182.95 \pm 0.03$ & $74.65 \pm 0.12$ & $43.03 \pm 0.07$ & $257.60 \pm 0.08$ \\
\hline Chemical control & $154.96 \pm 0.01$ & $58.43 \pm 0.10$ & $33.40 \pm 0.06$ & $213.39 \pm 0.01$ \\
\hline T85 & $194.95 \pm 0.02$ & $75.83 \pm 0.08$ & $34.82 \pm 0.01$ & $270.78 \pm 0.13$ \\
\hline T50 & $190.46 \pm 0.03$ & $67.95 \pm 0.08$ & $45.64 \pm 0.05$ & $258.41 \pm 0.21$ \\
\hline M14 & $183.04 \pm 0.04$ & $79.58 \pm 0.09$ & $37.70 \pm 0.04$ & $262.62 \pm 0.16$ \\
\hline M2_14 & $160.10 \pm 0.01$ & $60.47 \pm 0.14$ & $32.75 \pm 0.06$ & $220.57 \pm 0.25$ \\
\hline
\end{tabular}

The data are expressed as means \pm SDV (standard deviation) of three replicates of each experiment

Our findings are more or less similar to those reported by Alexandru et al. (2013) [32] which show that the differences between the pigments content of tomato plants treated to Trichoderma were insignificant but they found an increase of photosynthetic intensity. However, Mastouri et al. (2010) [23] reported no increase in pigment content in tomato seedlings treated with Trichoderma harzianum T22. According to the results of Azarmi et al. (2011) [12] chlorophyll content was not significantly increased in the leaves of tomato plants whose seeds have been treated with Trichoderma harzianum T969 and T447. Different contradictory results may be due to the use of different Trichoderma isolates with characteristic abilities, as well as the different varieties of tomatoes used.

\section{CONCLUSIONS}

Trichoderma isolates T85 and T50 are promising beneficial isolates, whose effects consist of growth promotion and an increase in physiological activity.

Plant height of tomatoes inoculated with T85 and T50 was increased compared to control.

Leaf number and root length of Trichoderma inoculated plants show no modifications compared to the control.

Three of Trichoderma isolates (T85, T50 and M14) tested have a positive influence on photosynthetic pigment content. 


\section{EXPERIMENTAL SECTION}

Seeds of tomato "Buzau 47" variety were obtained from Research and Development Station for Vegetables Buzau. Isolates of Trichoderma which have been used in this experiment were obtained from the collection at the Research and Development Institute for Plant Protection as following: T50 and T85- Trichoderma asperellum; M14-Trichoderma atroviride; M2_14Trichoderma citrinoviride. Each isolate was grown separately in Potato Dextrose Agar (PDA) plates and incubated for 7 days at $28^{\circ} \mathrm{C}$. Spore suspensions of Trichoderma spp. were prepared by scraping the spores from cultures. The concentration of Trichoderma spore suspension was counted using haemocytometer and was adjusted to $10^{7}$ spores $/ \mathrm{mL}$.

\section{Evaluation of tomato plant growth promoting response}

Tomato seeds were sterilized by soaking in $1 \%$ sodium hypochlorite solution $(\mathrm{NaClO})$ for 5 minutes, then in $70 \%$ ethanol for 5 minutes and finally washed for several times with sterile distilled water. The seeds were air dried in a sterile chamber. The sterilized tomato seeds

were immersed in $10 \mathrm{~mL}$ Trichoderma suspension $\left(10^{7}\right.$ spore $\left./ \mathrm{ml}\right)$ for 1 hour. Control seeds were treated with sterile distilled water. Seeds were sown in plastic pots filled with $250 \mathrm{~g}$ sterile soil and grown in a culture chamber where the temperature was maintained at $25^{\circ} \mathrm{C}$ with a relative humidity at $70 \%$ with $12 \mathrm{~h}$ light/dark photoperiod. The experiment was conducted using a total of with six variants (four Trichoderma isolates, one blank control and one chemical control). Chemical stimulant (Cropmax) was used in accordance to rate application on vegetables. Each treatment consisted of three replicates and the experiment was repeated twice.

\section{Measurement of physiological parameters}

Pigments of a known starting weight of leaves was extracted in acetone $100 \%(\mathrm{v} / \mathrm{v})$ over 24 hours at $4^{\circ} \mathrm{C}$. The obtained extracts were filtered through a Whatman No.1 filter paper and centrifuged at $5000 \mathrm{rpm}$ for 15 minutes. The chlorophyll (chla, chlb and total chl) and carotenoids content was quantified according to Lichtenthaler and Welburn, (1985) [33]. The absorbance was determined spectrophotometrically at $663 \mathrm{~nm}$ and $645 \mathrm{~nm}$ and $470 \mathrm{~nm}$. Concentration of pigments was calculated using Lichtenthaler \& Welburn, (1985) [33] equations and values were expressed as $(\mu \mathrm{g} / \mathrm{mL})$.

\section{Qualitative and quantitative estimation of phosphate solubilization in specific medium}

Two qualitative assays were used for phosphate solubilizing by Trichoderma isolates. For the phosphate solubilisation test, Trichoderma isolates were grown in the Pikovskaya's medium with bromophenol blue (BPB) and 574 
without it as described by Nautiyal, (1999) [34]. The medium contained the following ingredients ( $\left.\mathrm{g} \mathrm{L}^{-1}\right)$ : sucrose (24); $\mathrm{Ca}_{3}\left(\mathrm{PO}_{4}\right)(22) ; \mathrm{MgCl}_{2} \times 6 \mathrm{H}_{2} \mathrm{O}$ (22); $\mathrm{MgSO}_{4} \times 7 \mathrm{H}_{2} \mathrm{O}(0.25) ; \mathrm{KCl}(0.2) ;\left(\mathrm{NH}_{4}\right)_{2} \mathrm{SO}_{4}$ (0.1); $\mathrm{BPB}$ (0.025); agar (14). $\mathrm{pH}$ was adjusted to 7.00 .

Tribasic calcium phosphate was used as as phosphate source with BPB included in the Pikovskaya's medium as a $\mathrm{pH}$ indicator for acidification. After $72 \mathrm{~h}$ incubation at $25^{\circ} \mathrm{C}$ isolates turned the media from blue to yellow in zones of acidifications.

Another method used the same Pikovskaya's medium but without BPB. Appearance of cleared zones where calcium phosphate is consumed represented a positive response. The solubilization index was calculated by using the following formula:

Solubilization index =diameter of colony+halo zone /colony diameter

For the quantitative measurement of the phosphorus produced by the fungi cultures, they were grown in Pikovskaya's liquid medium amended with $0.5 \%$ insoluble $\mathrm{Ca}_{3}\left(\mathrm{PO}_{4}\right)_{2}$ and incubated for 5 days with shaking $(120 \mathrm{rpm})$ at $28 \pm 2^{\circ} \mathrm{C}$. The supernatant of each culture was centrifuged at 6000rpm for $25 \mathrm{~min}$. The soluble phosphorus was determined using the procedure described by Fiske \& Subbarow (1925) [35] and Saravanakumar et al. (2013) [36]. The concentration of soluble phosphorus $(P)$ was calculated by using a standard curve of $\mathrm{KH}_{2} \mathrm{PO}_{4}$ and expressed in $\mathrm{mg} / \mathrm{l}$.

\section{Quantification of indole-3acetic acid (IAA) produced by fungi}

Theour isolates belonging to different fungal species were subjected to IAA screening during this investigation. PDB liquid medium with $0.1 \% \mathrm{~L}$ tryptophan $(\mathrm{w} / \mathrm{v})$ was inoculated with two disks of one week old culture of each tested fungus isolates and incubated at $28^{\circ} \mathrm{C}$ for 6 days as a stationary cultivation. Estimation of IAA-like auxines in the culture filtrate was conducted by using colorimetric technique with Salkowski reagent [37]. Mycelia were removed by centrifugation ( $5000 \mathrm{rpm}, 10$ minute), and afterwards by filtration. $1 \mathrm{ml}$ of the supernatant was mixed with $4 \mathrm{ml}$ of Salkowsky reagent (35\% perchloric acid; $0.5 \mathrm{M}$ ferric chloride, $\mathrm{FeCl}_{3}$ ). To determine the amount of IAA produced by the isolates, the mixture was incubated at room temperature for 25 minutes. Pink colouration developed, indicating the presence of IAA, and it was quantified by measuring the absorbance in a spectrophotometer at 535 $\mathrm{nm}$ at the end of the incubation. The concentration of IAA was evaluated by comparison with standard curve and expressed as $\mu \mathrm{g} / \mathrm{ml}$.

\section{Measurement of tomato growth traits}

Tomato growth parameters were measured at 30 days after germination.

Plant height $(\mathrm{cm})$ was measured from ground level to the tip of the longest leaf, leaf number were counted for each treatment and controls. 
Root length $(\mathrm{cm})$ was measured from the base of stem to the longest root using a ruler. Root dry weight $(\mathrm{g})$ was measured after drying the roots in the oven at $105^{\circ} \mathrm{C}$ until obtaining a constant weight.

\section{REFERENCES}

1. G.E. Harman, Plant Diseases, 2000, 84, 377

2. R. Hermosa, A. Viterbo, I. Chet, E. Monte, Microbiology, 2012, 158, 17

3. F. Vinale, K. Sivasithamparam, E.L. Ghisalberti, R. Marra, S.L. Woo, M. Lorito, Soil Biology and Biochemistry, 2008, 40, 1

4. Y.C. Chang, R. Baker, O. Kleifeld, I Chet, Plant Diseases, 1986, 70, 145

5. G. Colla, Y. Rouphel, E. Di Mattia, C. El-Nakhel, M. Cardarelli, Journal of Science Food and Agriculture, 2015, 95, 1706

6. H.A. Contreras-Cornejo, I. Macias-Rodriguez, C. Cortes-Penagos, J. LopezBucio, Plant Physiology, 2009, 149, 1579

7. F. Doni, A. Isahak, C.R.CM. Zain, W.M.V. Yusoff, Amb Express, 2014, 4(35),1

8. G.E. Harman, T. Bjorkman, in Harman \& Kubicek (ed): Trichoderma and Gliocladium. Vol 2, 229-265., Taylor \& Francis, London 1998, cap 11.

9. I. Hoyos-Carvajal, S. Orduz, J.Bissett, Biological Control, 2009, 51(3), 409.

10. J. Lopez-Bucio, R. Pelagio-Flores, A. Herrera-Estrella, Scientia Horticulture, 2015, 196, 109

11. M.T. Windham, Y. Elad, R. Baker, Phytopathology, 1986, 76, 518

12. R. Azarmi, B. Hajieghrari, A. Griglou, African Journal of Biotechnology, 2011,10, 5850

13. M. Entesari, F. Sharifzadeh, M. Ahmadzadeh, M. Farhangfar, International Journal of Agronomy Plant Production, 2013, 4(4), 610

14. V. Gravel, H. Antoun, J. Russell, T. Weddell, Soil Biology and Biochemistry, 2007, 40, 1

15. B. Nzanza, D. Marais, P. Soundy, Scientia Horticulture (amst), 2012, 144, 55

16. J.G. Ortega-Garcia, R. Montes-Belmont, M. Rodriguez-Monroy, J.A.RamirezTrujillo, R. Suarez- Rodriguez, G. Sepulveda-Jimenez, Scientia Horticulture, 2015, 195, 8

17. M. Tucci, M. Rucco, I. De Masi, M. De Palma, M. Lorito, Molecular Plant Pathology, 2011, 12(4), 341

18. J. Yadov, J. Verma- Prakash, K. Tiwari-Nath, Asian Journal Biologic Sciences, 2011, 4(3), 291

19. I. Zhao, Y.J. Zhang, Integrative Agriculture, 2015, 14(8), 1588

20. J.T. De Souza, B.A. Bailey, A.W.V. Pomella, E.F. Erbe, C.A. Murphy, H. Bae, P.K. Hebbar, Biological Control, 2008, 46, 36

21. C. Altomare, W.A. Norvell, T. Bjorkman, G.B. Harman, Applied Environmental Microbiology, 1999, 65, 2926

22. P. Chowdappa, S.P. Mohan Kumar, M.J. Lakshami, K.K. Upreti, Biological Control, 2013, 6, 109 


\section{PHYSIOLOGICAL AND GROWTH RESPONSE OF TOMATO PLANTS AFTER TRICHODERMA SPP. SEED TREATMENTS}

23. F. Mastouri, T. Bojorkman, G.E. Harman, Phytopatology, 2010, 100(11), 1213

24. R.S.R. El-Mohamedy, M.M.H. Abd El-Baky, Research Journal of Agriculture and Biological Sciences, 2008, 4, 611

25. R. Mukhopadhay, S.J. Pan, Plant Protection Science, 2012, 4(2), 46

26. N. Ozbay, S.E. Newman, W.M. Brown, Acta Horticulture, 2004, 635,131

27. S.S. Jang, J.K. Han, C.S. Park, K.H. Kim, J. Korean, Plant Pathology, 1993, 9(3), 149

28. A. Kotasthane, T. Agrawal, R. Kushwash, O.V. Rahatkar, European Journal Plant Pathology, 2015, 141, 523

29. M.A. Salas-Marina, M.A. Silva-Flores, E.E. Uresti-Rivera, E. Castro-Longoria, A. Herrera-Estrella, S. Casas-Flores, European Journal of Plant Pathology, 2011, 131, 15

30. I. Fiorini, I. Guglielminetti, I. Mariotti, M. Curadi, P. Picciarelli, A. Scartazza, S. Sarrocco, G. Vannacci, Plant Soil, 2016, 400, 351

31. A. Sofo, A. Scopa, M. Manfra, M. De Nisco, G. Tenore, J. Troisi, R. Di Fiori, E. Novellino, Plant Growth Regulation, 2011, 65, 421

32. M. Alexandru, D. Lazar, M. Ene, T.E. Sesan, Romanian Biotechnological Letter, 2013, 18, 8499

33. H.K. Lichtenthaler, A.R. Wellburn, Biochemistry Society Transaction,1985, 11, 591

34. C.S. Nautiyal, FEMS Microbiology Letters, 1999, 170, 265-270

35. C.H. Fiske, Y.J. Subbarow, Biological Chemistry, 1925, 66, 375

36. K. Saravanakumar, V.S. Arasu, K. Kathiresan, Aquatic Botany, 2013, 104, 101

37. S.A. Gordon, R.P. Weber, Plant Physiology, 1951, 26, 192 